\title{
DOES BODY FAT MASS DEFINE SURVIVAL IN PATIENTS STARTING PERITONEAL DIALYSIS?
}

\author{
Soo Jeong Choi, Eun Jung Kim, Moo Yong Park, Jin Kuk Kim, and Seung Duk Hwang \\ Department of Internal Medicine, Soonchunhyang University College of Medicine, \\ Bucheon Hospital, Korea
}

- Background and Aims: Peritoneal dialysis (PD) is characterized by a gain in fat mass. Unlike subcutaneous fat, visceral fat is associated with metabolic syndrome and survival. We prospectively examined whether visceral or subcutaneous fat could predict outcome in patients undergoing PD.

- Methods: We studied 117 new patients (57 men) undergoing PD between February 2006 and November 2011. Baseline body composition was measured on computed tomograms. Visceral obesity was defined as a visceral fat area exceeding $100 \mathrm{~cm}^{2}$, and subcutaneous obesity, as a subcutaneous fat area exceeding $130 \mathrm{~cm}^{2}$.

- Results: Among the 117 patients, 37 and 29 were diagnosed with visceral and subcutaneous obesity respectively. Visceral and subcutaneous obesity were both present in 21 patients. In the study population, the 1-year and 5-year survival rates were $94 \%$ and $59 \%$. The rates of peritonitis and exit-infection were 0.31 and 0.14 episodes per patient-year. Mortality was greater in patients with visceral obesity than in those without visceral obesity $(p=0.005)$. Visceral obesity had no influence on peritonitis and exit-infection rates. Subcutaneous obesity was associated neither with survival nor with peritonitis or exit-site infection. In a multivariate Cox regression analysis, visceral obesity was not a risk factor for poor outcome.

- Conclusions: Increased visceral fat at PD initiation is not an independent predictor of poor survival. Any impact of visceral or subcutaneous fat mass on outcomes in patients undergoing PD would be better defined by larger, longterm studies.

Perit Dial Int 2014; 34(4):376-382 www.PDIConnect.com epub ahead of print: 01 Feb 2013 doi:10.3747/pdi.2011.00152

KEY WORDS: Body composition.

Correspondence to: S.D. Hwang, Division of Nephrology, Department of Medicine, Soonchunhyang University Bucheon Hospital, 170 Jomaru-ro, Wonmi-gu, Bucheon-si, Gyeonggi-do 420-767 Republic of Korea.

sd7hwang@schmc.ac.kr

Received 3 July 2011; accepted 4 July 2012
Tn contrast to subcutaneous fat mass, visceral fat mass Iis more often associated with metabolic syndrome and atherosclerosis in both obese and normal-weight individuals (1). Additionally, compared with change in subcutaneous fat mass, change in visceral fat mass is a more reliable predictor of survival in peritoneal dialysis (PD) patients (2). Although some studies have indicated that high body mass index (BMI) is a predictor of good prognosis $(3,4)$, obesity is a risk factor for peritonitis (5). Furthermore, BMI does not reflect hydration status in patients undergoing PD. Thus, some studies have attempted to identify the impact of visceral and subcutaneous fat on survival during PD $(6,7)$. We examined whether either visceral or subcutaneous fat mass is associated with outcome in patients undergoing PD.

\section{METHODS}

Our study was approved by the institutional review board of Soonchunhyang University Bucheon Hospital (SCHBC-IRB-10-19). We prospectively collected data for patients who started and maintained continuous ambulatory or automated PD for at least 6 months at our hospital. Exclusion criteria were age less than 18 years, current malignancy, and a life expectancy shorter than 6 months after PD start.

The primary outcome was death from any cause. Kidney transplantation, change to hemodialysis, transfer to another hospital, and patient withdrawal were censored observations. Secondary outcomes were peritonitis and exit-site infection.

Baseline data, including age, sex, weight, underlying renal disease, and presence of comorbid diseases such as diabetes mellitus (DM), hypertension, and cardiovascular disease (CVD) were collected. Body weight was determined after the abdomen had been filled with $2 \mathrm{~L}$ of dialysate. Cardiovascular disease was defined as the presence of coronary artery disease, congestive heart failure, cerebrovascular accident, or peripheral vascular disease. 
Body mass index was calculated using the formula

$$
\text { BMI }=\text { weight }(\mathrm{kg}) / \text { height }\left(\mathrm{m}^{2}\right) \text {. }
$$

Obesity was defined as a BMI exceeding $25 \mathrm{~kg} / \mathrm{m}^{2}$.

\section{NUTRITION PARAMETERS AND SEROLOGY MARKERS}

Blood samples were obtained on day 7 after the start of PD. The subjective global assessment for nutrition status was performed at the same time. Normalized protein equivalent of nitrogen appearance (8) and lean body mass (9), based on creatinine kinetics, were estimated from the results of an adequacy assessment using 24-hour effluent and urine.

For the subjective global assessment, we used a 7-point Likert-type scale to assess four items (10): weight loss, anorexia, subcutaneous fat, and muscle mass. The item scores were totalled to produce a global assessment. Scores of $1-2$ represent severe malnutrition; $3-5$, moderate-to-mild malnutrition; and $6-7$, normal nutrition.

Skinfold thickness was measured at the biceps using conventional skinfold calipers (Skyndex: Caldwell, Justice and Co., Fayetteville, AR, USA). Mid-arm circumference was measured three times, and the mean value was recorded.

\section{BODY COMPOSITION ASSESSMENT}

We measured body composition using bioelectric impedance analysis (BIA: Inbody, Biospace, Seoul, Korea) on day 7 after PD start. Patients underwent BIA without socks and shoes after a dialysate fill. Multi-frequency $\operatorname{BIA}(5,50,250$, and $500 \mathrm{kHz})$ reveals extracellular fluid, intracellular fluid, protein, mineral, and fat mass.

We measured visceral and subcutaneous fat mass using abdominal computed tomography (CT/1 Pro: GE Healthcare, Milwaukee, WI, USA) on day 7 after PD start. All subjects were examined in the supine position with both arms stretched above the head. One acquisition was made at the umbilicus level, with a slice thickness of $10 \mathrm{~mm}$; exposure time varied from $3 \mathrm{~s}$ to $11 \mathrm{~s}$. The radiation dose for the fat imaging was $1.15 \mathrm{mSv}$. Total adipose tissue area was calculated by delineating the abdomen with an electronic graph pen and computing the adipose tissue surface using an attenuation range of $-150 \mathrm{HU}$ to $-50 \mathrm{HU}$. Visceral fat was distinguished from subcutaneous fat by tracing along the facial plane to define the internal abdominal wall. The area of each compartment was measured in square centimeters.

We defined visceral obesity as a visceral fat area (VFA) exceeding $100 \mathrm{~cm}^{2}(11,12)$ and subcutaneous obesity as a subcutaneous fat area (SFA) exceeding $130 \mathrm{~cm}^{2}$ (13).

\section{STATISTICAL ANALYSIS}

Data are expressed as mean \pm standard deviation. Statistical differences were analyzed using the Student t-test, the chi-square test, and the Pearson correlation, as appropriate. Logistic regression analysis was used to predict variables of visceral and subcutaneous obesity. Survival rates were analyzed using Kaplan-Meier survival curves. The log-rank test was used to test differences between survival curves. A Cox proportional hazards model was used to identify independent predictors of primary and secondary outcomes. Values of $p<0.05$ were taken to indicate statistical significance. All statistical calculations were performed using the SPSS software package (version 14.0: SPSS, Chicago, IL, USA).

\section{RESULTS}

\section{PATIENT CHARACTERISTICS}

Of 126 patients who started PD between February 2006 and November 2011, 4 were excluded because of a life expectancy of less than 6 months, and 5, because of refusal of informed consent. Thus, 117 patients were included in the study.

Table 1 shows the baseline clinical characteristics for the study patients. Mean age was $54.0 \pm 13.3$ years (range: 23 - 91 years). In this group, 59 patients $(50.4 \%)$ had DM, and $43(36.8 \%)$ had CVD.

\section{NUTRITION STATUS AND FAT MASS AT PD START}

Table 2 shows body composition, anthropometrics, and laboratory results for the patients at the start of PD. Compared with female patients, male patients weighed more and had higher serum creatinine and lower hematocrit and cholesterol. Body composition-including intracellular fluid, extracellular fluid, protein, and mineral mass-was greater in men than in women. Percentage body fat was greater in women than in men.

\section{BASELINE FACTORS ASSOCIATED WITH FAT COMPOSITION}

In 38 patients $(32.5 \%)$, BMI exceeded $25 \mathrm{~kg} / \mathrm{m}^{2}$ [Figure $1(\mathrm{~A})$ ]. Visceral obesity was diagnosed in 37 patients (31.6\%), and subcutaneous obesity, in 29 $[24.8 \%$, Figure $1(B, C)]$. Visceral and subcutaneous obesity were both present in 21 patients (17.9\%). After adjustments for age, sex, DM, and CVD, baseline VFA and SFA were associated with weight, triglycerides, intracellular fluid, protein mass, fat mass, mid-arm circumference, skinfold thickness, and BMI (data not shown). Baseline 
TABLE 1

Characteristics of the Study Population

\begin{tabular}{lc}
\hline \multicolumn{1}{c}{ Variable } & Value \\
\hline Patients $(n)$ & 117 \\
Sex $[n(\%)]$ & \\
$\quad$ Men & $57(48.7)$ \\
$\quad$ Women & $60(51.3)$ \\
Diabetes $[n(\%)]$ & $59(50.9)$ \\
CVD $[n(\%)]$ & $43(36.8)$ \\
Modality $(n$ CAPD/APD/combined) & $50 / 53 / 14$ \\
Age $($ years $)$ & $54.0 \pm 13.3$ \\
Height $(\mathrm{cm})$ & $161.2 \pm 11.5$ \\
Weight $(\mathrm{kg})$ & $61.2 \pm 11.5$ \\
Body mass index $\left(\mathrm{kg} / \mathrm{m}^{2}\right)$ & $23.5 \pm 3.2$ \\
Hematocrit $(\%)$ & $31.0 \pm 4.6$ \\
Creatinine $(\mathrm{mg} / \mathrm{dL})$ & $8.2 \pm 2.8$ \\
Albumin $(\mathrm{g} / \mathrm{dL})$ & $3.9 \pm 0.8$ \\
Cholesterol $(\mathrm{mg} / \mathrm{dL})$ & $152.5 \pm 42.9$ \\
Triglycerides $(\mathrm{mg} / \mathrm{dL})$ & $121.6 \pm 86.7$ \\
hs-CRP $(\mathrm{mg} / \mathrm{dL})$ & $0.8 \pm 1.5$ \\
HbA1c $(\%)$ & $5.8 \pm 1.2$ \\
\hline
\end{tabular}

$C V D=$ cardiovascular disease $;$ CAPD = continuous ambulatory peritoneal dialysis; $\mathrm{APD}=$ automated peritoneal dialysis; hs-CRP $=$ high sensitivity $C$-reactive protein .

VFA was correlated with SFA. Table 3 shows the predictors for visceral and subcutaneous obesity at the start of PD. Although many variables were predictors of visceral and subcutaneous obesity by univariate logistic regression analysis, multivariate logistic regression analysis showed that female sex, weight, and visceral-to-subcutaneous fat ratio were predictors of visceral and subcutaneous obesity. Age was a risk factor for visceral obesity.

\section{FOLLOW-UP NUTRITION STATUS AND FAT MASS}

Patient Survival: During the observation period [36.1 \pm 20.2 months (range: 1 - 76 months)], 23 PD patients (19.7\%) died. Another 5 patients underwent kidney transplantation, 22 changed to hemodialysis (HD), and 5 transferred to other hospitals. In the study cohort, the 1-year and 5-year survival rates were $94 \%$ and $59 \%$ respectively.

Univariate Cox regression analysis showed that several variables at the start of PD-including age, DM, CVD, triglycerides, creatinine, fat mass, fat mass percentage, visceral-to-subcutaneous fat ratio, and visceral obesitywere closely related to survival. Compared with patients not having visceral obesity, those with visceral obesity experienced poorer survival (Figure 2). However, a multivariate Cox regression analysis model that included age,
TABLE 2

Body Composition and Anthropometrics of the Study Population at Peritoneal Dialysis Start

\begin{tabular}{|c|c|c|c|}
\hline Variable & $\begin{array}{l}\text { Men } \\
(n=57)\end{array}$ & $\begin{array}{l}\text { Women } \\
(n=60)\end{array}$ & $\begin{array}{c}p \\
\text { Value }\end{array}$ \\
\hline Age (years) & $51.6 \pm 13.0$ & $56.2 \pm 13.2$ & 0.064 \\
\hline Weight (kg) & $68.1 \pm 10.0$ & $54.8 \pm 8.8$ & 0.000 \\
\hline $\begin{array}{l}\text { Body mass index } \\
\left(\mathrm{kg} / \mathrm{m}^{2}\right)\end{array}$ & $24.1 \pm 3.1$ & $23.0 \pm 3.3$ & 0.090 \\
\hline Hematocrit (\%) & $30.1 \pm 4.1$ & $32.0 \pm 4.9$ & 0.026 \\
\hline Creatinine $(\mathrm{mg} / \mathrm{dL})$ & $9.7 \pm 2.8$ & $6.9 \pm 1.9$ & 0.000 \\
\hline Albumin (g/dL) & $3.8 \pm 0.5$ & $3.9 \pm 0.9$ & 0.411 \\
\hline Cholesterol (mg/dL) & $133.6 \pm 35.0$ & $170.4 \pm 42.3$ & 0.000 \\
\hline Triglycerides (mg/dL) & $105.5 \pm 74.9$ & $136.6 \pm 94.6$ & 0.055 \\
\hline hs-CRP (mg/dL) & $1.0 \pm 1.3$ & $0.6 \pm 1.7$ & 0.227 \\
\hline HbA1c (\%) & $5.9 \pm 1.1$ & $5.7 \pm 1.2$ & 0.364 \\
\hline Intracellular fluid (L) & $24.5 \pm 3.6$ & $17.7 \pm 2.9$ & 0.000 \\
\hline Extracellular fluid (L) & $14.0 \pm 2.6$ & $11.5 \pm 6.2$ & 0.008 \\
\hline Protein mass $(\mathrm{kg})$ & $13.3 \pm 2.0$ & $9.7 \pm 1.7$ & 0.000 \\
\hline Mineral mass $(\mathrm{kg})$ & $3.4 \pm 1.4$ & $2.7 \pm 1.2$ & 0.011 \\
\hline Fat mass $(\mathrm{kg})$ & $13.1 \pm 5.7$ & $13.8 \pm 6.2$ & 0.502 \\
\hline $\begin{array}{l}\text { Percentage body } \\
\text { fat }(\%)\end{array}$ & $18.8 \pm 6.2$ & $25.1 \pm 8.1$ & 0.000 \\
\hline Visceral fat area $\left(\mathrm{cm}^{2}\right)$ & $85.7 \pm 58.1$ & $84.2 \pm 56.1$ & 0.885 \\
\hline $\begin{array}{l}\text { Subcutaneous fat } \\
\text { area }\left(\mathrm{cm}^{2}\right)\end{array}$ & $94.7 \pm 52.5$ & $110.9 \pm 67.9$ & 0.153 \\
\hline $\begin{array}{l}\text { Mid-arm } \\
\text { circumference }(\mathrm{cm})\end{array}$ & $28.5 \pm 3.0$ & $27.2 \pm 7.2$ & 0.110 \\
\hline $\begin{array}{l}\text { Skinfold thickness } \\
(\mathrm{cm})\end{array}$ & $22.4 \pm 7.2$ & $22.4 \pm 7.2$ & 0.962 \\
\hline SGA score & $26.2 \pm 7.5$ & $25.5 \pm 2.9$ & 0.098 \\
\hline nPNA (g/kg/day) & $1.04 \pm 0.24$ & $1.08 \pm 0.30$ & 0.453 \\
\hline Total Kt/V & $2.18 \pm 1.80$ & $2.53 \pm 1.31$ & 0.236 \\
\hline Diabetes & 29 & 30 & 0.855 \\
\hline Cardiovascular disease & 23 & 20 & 0.450 \\
\hline
\end{tabular}

hs-CRP = high sensitivity $\mathrm{C}$-reactive protein; $\mathrm{SGA}=$ subjective global assessment; $\mathrm{nPNA}=$ normalized equivalent of protein nitrogen appearance.

sex, DM, CVD, visceral obesity, creatinine, triglycerides, high-sensitivity C-reactive protein, and normalized protein equivalent of nitrogen appearance revealed that only age and serum creatinine were independent risk factors for a poor prognosis (Table 4).

Peritonitis and Exit-Site Infection: During the study period, 49 patients experienced a mean of $2.3 \pm 1.5$ episodes of peritonitis (range: 1 - 6 episodes), and 25 patients experienced a mean of $2.0 \pm 1.4$ exit-site infections (range: $1-6$ infections). The peritonitis and exit-site infection rates were, respectively, 0.31 and 0.14 episodes per patient-year. Univariate Cox regression 

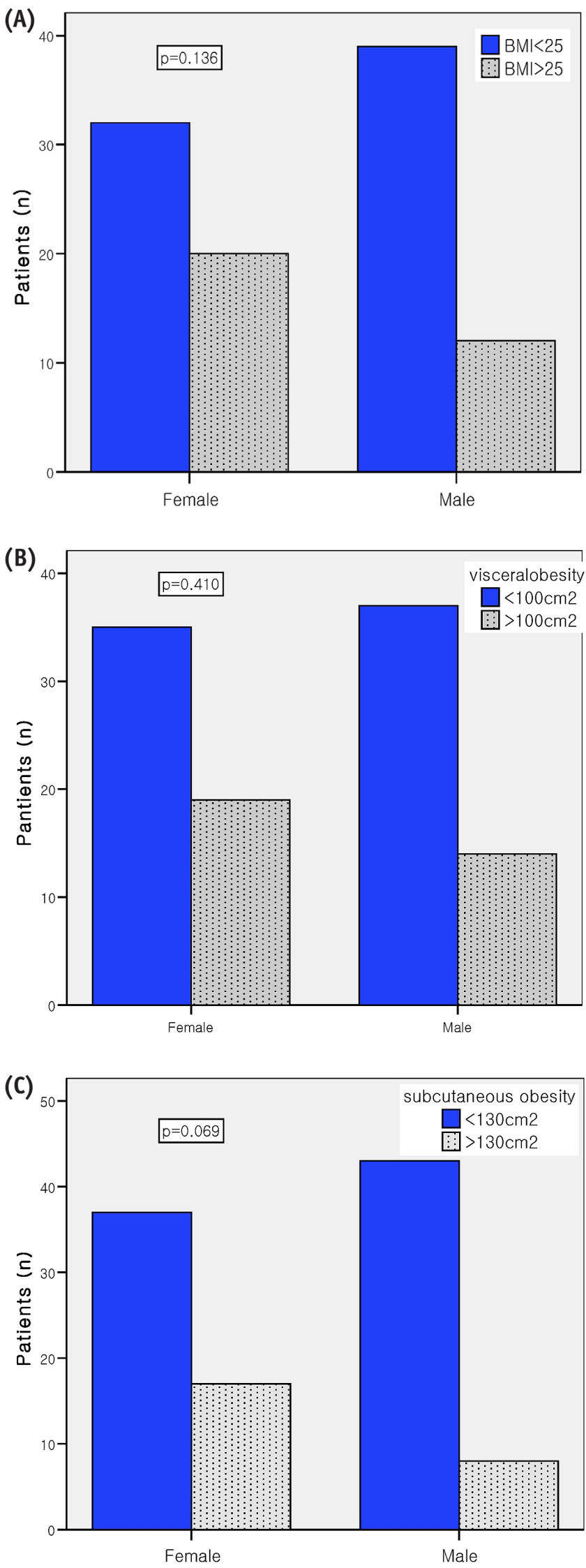

Figure 1-Comparison of (A) obesity, (B) visceral obesity, and (C) subcutaneous obesity, by sex. analysis showed that none of the studied variables were associated with peritonitis and exit-site infection.

\section{DISCUSSION}

An increase in body fat is a common finding in patients undergoing PD $(14,15)$. Excess adipose tissue, particularly visceral fat, is associated with insulin resistance, hyperglycemia, dyslipidemia, hypertension, and prothrombotic and proinflammatory states in patients undergoing dialysis (1,16-18). Those conditions may predict the development of protein-energy wasting (19).

Some reports have indicated that a high BMI is a predictor of good prognosis $(3,4)$; however, BMI does not reflect hydration status, and being overweight is a known risk factor for survival $(5,20,21)$. Given that patients undergoing PD have continuously fluctuating weight according to use of dialysate, we analyzed visceral and subcutaneous fat areas by computed tomography. In our previous study (7), body weight increased continuously during a 12-month study period, but visceral and subcutaneous fat mass did not change during that time. In the present study, we showed the clinical significance of separating visceral and subcutaneous fat. Neither visceral nor subcutaneous fat mass differed according to sex (Table 2), but female sex was associated with visceral and subcutaneous obesity (Table 3 ). Those findings contrast with the results published by Sanches et al. (17), who conducted a cross-sectional study in patients with non-dialysis chronic kidney disease, showing that visceral fat was greater in men than in women and that subcutaneous fat was greater in women.

We determined visceral and subcutaneous obesity based on the definitions proposed by other investigators-that is, VFA greater than $100 \mathrm{~cm}^{2}$ and SFA greater than $130 \mathrm{~cm}^{2}$ (11-13). In the present study, visceral obesity was associated with poorer survival (Figure 2), but it was not a risk factor for poor survival according to the multivariate Cox regression analysis. Visceral obesity was not associated with peritonitis and exit-infection (data not shown). Obesity (BMI > 25) was not associated with mortality in our study (data not shown). Those results are consistent with the results of Cordeiro et al. (22), who used a conicity index for abdominal fat deposition. Because BMI does not distinguish between muscle and fat, those authors proposed a useful tool to identify individuals who have abdominal obesity, but who are not necessarily obese or overweight. In contrast, we analyzed the impact of volume overload, as in a previous report (23). However, the extracellular-to-intracellular water ratio is not a predictor of survival in patients undergoing $P D$. Caution should be used when interpreting volume 
TABLE 3

Predictors of Visceral and Subcutaneous Obesity at Peritoneal Dialysis Start

\begin{tabular}{|c|c|c|c|c|c|c|}
\hline \multirow[b]{2}{*}{ Predictor } & \multicolumn{3}{|c|}{ Visceral obesity } & \multicolumn{3}{|c|}{ Subcutaneous obesity } \\
\hline & $p$ Value & $\operatorname{Exp}(B)$ & $95 \%$ CI & $p$ Value & $\operatorname{Exp}(B)$ & $95 \%$ CI \\
\hline \multicolumn{7}{|l|}{ Univariate } \\
\hline Age (years) & 0.006 & 1.047 & 1.014 to 1.082 & 0.722 & 1.006 & 0.974 to 1.038 \\
\hline Sex (female) & 0.421 & 1.380 & 0.630 to 3.023 & 0.080 & 2.178 & 0.910 to 5.213 \\
\hline Weight (kg) & 0.001 & 1.068 & 1.026 to 1.111 & 0.001 & 1.079 & 1.032 to 1.128 \\
\hline History of CVD & 0.028 & 2.463 & 1.104 to 5.496 & 0.300 & 0.637 & 0.271 to 1.496 \\
\hline Hematocrit (\%) & 0.031 & 0.903 & 0.823 to 0.991 & 0.092 & 0.919 & 0.834 to 1.014 \\
\hline Triglycerides (mg/dL) & 0.004 & 1.008 & 1.003 to 1.014 & 0.013 & 1.006 & 1.001 to 1.012 \\
\hline $\operatorname{BMI}\left(\mathrm{kg} / \mathrm{m}^{2}\right)$ & 0.000 & 1.496 & 1.257 to 1.781 & 0.000 & 1.710 & 1.369 to 2.135 \\
\hline Fat mass (kg) & 0.000 & 1.328 & 1.158 to 1.522 & 0.000 & 1.369 & 1.187 to 1.576 \\
\hline $\mathrm{V} / \mathrm{S}$ ratio & 0.001 & 7.475 & 2.563 to 27.796 & 0.057 & 0.319 & 0.098 to 1.035 \\
\hline $\operatorname{MAC}(\mathrm{cm})$ & 0.001 & 1.340 & 1.121 to 1.601 & 0.001 & 1.926 & 1.315 to 2.819 \\
\hline Skinfold thickness (cm) & 0.039 & 1.067 & 1.003 to 1.136 & 0.002 & 1.114 & 1.039 to 1.195 \\
\hline \multicolumn{7}{|l|}{ Multivariate $^{\mathrm{a}}$} \\
\hline Sex (female) & 0.001 & 35.435 & 4.675 to 268.572 & 0.009 & 20.375 & 2.106 to 197.09 \\
\hline Age & 0.019 & 1.077 & 1.012 to 1.146 & 0.162 & 1.050 & 0.981 to 1.124 \\
\hline Weight & 0.000 & 1.253 & 1.119 to 1.403 & 0.028 & 1.165 & 1.016 to 1.336 \\
\hline V/S ratio & 0.000 & 15.458 & 3.446 to 69.329 & 0.008 & 0.017 & 0.001 to 0.350 \\
\hline
\end{tabular}

$\mathrm{CI}=$ confidence interval; $\mathrm{CVD}=$ cardiovascular disease; $\mathrm{BMI}=$ body mass index; $\mathrm{V} / \mathrm{S}$ ratio = visceral-to-subcutaneous fat ratio; $M A C=$ mid-arm circumference.

${ }^{a}$ Model included sex, age, weight, history of CVD, diabetes, hematocrit, triglycerides, and visceral-to-subcutaneous fat ratio.

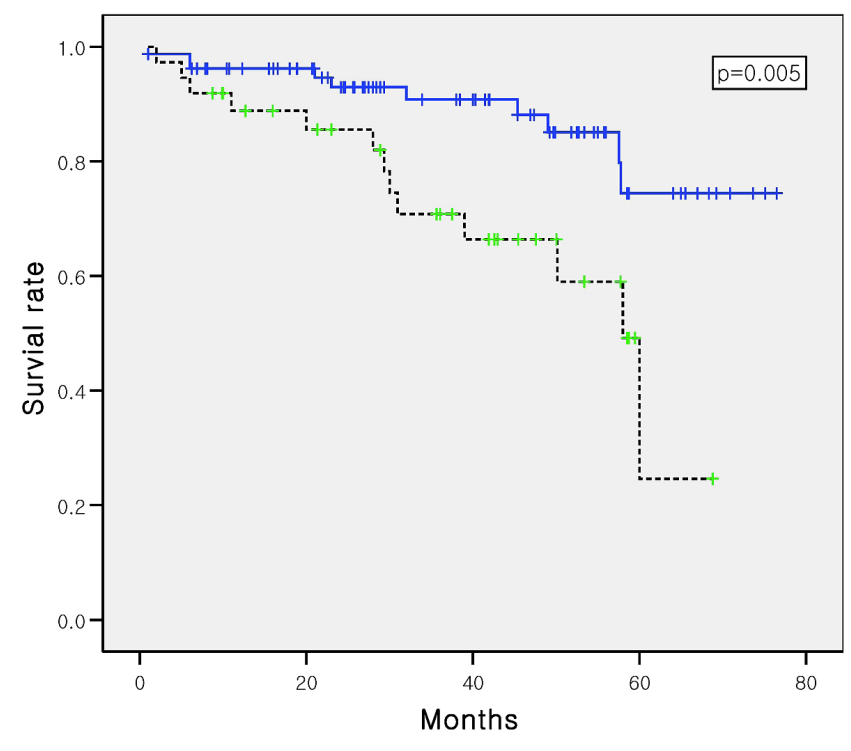

Figure 2 - Kaplan-Meier survival curves for patients with (dotted line) and without (solid line) visceral obesity (logrank $p=0.005)$.

status in PD patients, because body fluid distribution is influenced by nutrition status, aging, and sex $(24,25)$.

As in our previous study (7), we found that visceral and subcutaneous fat did not change, leading us to hypothesize that initial visceral or subcutaneous fat mass influences patient outcome. The visceral and subcutaneous fat masses are biologically distinct $(26,27)$. Axelsson et al. (28) showed that the relationship between fat mass and inflammatory biomarkers differed for truncal and non-truncal fat mass. McDonald et al. (5) showed that a higher BMI at the commencement of PD is a significant risk factor for peritonitis, although the mechanism is unknown. Those authors suggested some possible reasons, including the greater difficulty that obese patients might experience with exit-site care and assessment, and a greater tendency toward underdialysis in obese patients. Our study did not find visceral or subcutaneous obesity to be a risk factor for exit-site infection, peritonitis, or survival. Other reports using body weight have been unable to determine a significant effect of body size on the risk for peritonitis $(29,30)$. Twardowski and Prowant reported that a high BMI was associated with an increased risk for early exit-site infection (31).

Contrary to our expectation, multivariate Cox regression did not demonstrate a clinical impact of visceral or subcutaneous fat mass on outcome. It showed that age and serum creatinine at the start of PD were associated with survival. We therefore suggest that increased visceral fat at the initiation of PD is not an independent predictor of poor outcome. 
TABLE 4

Predictors of Mortality by Univariate and Multivariate Cox Analysis

\begin{tabular}{|c|c|c|c|c|c|c|}
\hline \multirow[b]{2}{*}{ Predictor } & \multicolumn{3}{|c|}{ Univariate } & \multicolumn{3}{|c|}{ Multivariate ${ }^{a}$} \\
\hline & $p$ Value & $\operatorname{Exp}(B)$ & $95 \% \mathrm{CI}$ & $p$ Value & $\operatorname{Exp}(B)$ & $95 \% \mathrm{CI}$ \\
\hline Age (years) & 0.000 & 1.104 & 1.062 to 1.148 & 0.034 & 1.058 & 1.004 to 1.115 \\
\hline Sex (female) & 0.285 & 1.601 & 0.676 to 3.791 & 0.508 & 1.465 & 0.473 to 4.533 \\
\hline Diabetes (present) & 0.007 & 3.635 & 1.423 to 9.286 & 0.605 & 1.413 & 0.381 to 5.239 \\
\hline History of CVD & 0.003 & 3.615 & 1.485 to 8.803 & 0.360 & 1.721 & 0.539 to 5.499 \\
\hline $\operatorname{BMI}\left(\mathrm{kg} / \mathrm{m}^{2}\right)$ & 0.783 & 1.016 & 0.907 to 1.138 & & & \\
\hline Weight $(\mathrm{kg})$ & 0.697 & 0.993 & 0.956 to 1.031 & & & \\
\hline Creatinine $(\mathrm{mg} / \mathrm{dL})$ & 0.000 & 0.649 & 0.510 to 0.827 & 0.049 & 0.725 & 0.527 to 0.999 \\
\hline hs-CRP (mg/dL) & 0.118 & 1.198 & 0.955 to 1.501 & 0.469 & 1.108 & 0.840 to 1.462 \\
\hline Triglycerides (mg/dL) & 0.045 & 1.004 & 1.000 to 1.007 & 0.291 & 1.002 & 0.998 to 1.007 \\
\hline \multicolumn{7}{|l|}{ Obesity } \\
\hline Visceral & 0.007 & 3.098 & 1.353 to 7.094 & 0.655 & 1.320 & 0.391 to 4.458 \\
\hline Subcutaneous & 0.358 & 1.519 & 0.623 to 3.702 & & & \\
\hline Intracellular fluid (L) & 0.058 & 0.893 & 0.794 to 1.004 & & & \\
\hline Fat mass $(\mathrm{kg})$ & 0.009 & 1.074 & 1.018 to 1.133 & & & \\
\hline Fat percentage (\%) & 0.000 & 1.098 & 1.042 to 1.156 & & & \\
\hline $\mathrm{V} / \mathrm{S}$ ratio & 0.001 & 1.389 & 1.146 to 1.684 & & & \\
\hline nPNA (g/kg/day) & 0.021 & 0.112 & 0.017 to 0.717 & 0.071 & 0.208 & 0.038 to 1.142 \\
\hline
\end{tabular}

$\mathrm{CI}=$ confidence interval; $\mathrm{CVD}=$ cardiovascular disease; $\mathrm{BMI}=$ body mass index; $\mathrm{hs}-\mathrm{CRP}=$ high sensitivity $\mathrm{C}$-reactive protein; $\mathrm{V} / \mathrm{S}$ ratio $=$ visceral-to-subcutaneous fat ratio; $\mathrm{nPNA}=$ normalized equivalent of protein nitrogen appearance.

a Model included age, sex, diabetes status, history of CVD, visceral obesity, creatinine, triglycerides, hs-CRP, and nPNA.

To the best of our knowledge, this report is the first to use determination of fat mass by computed tomography to investigate the clinical significance of visceral and subcutaneous fat in patients with PD. Despite subanalyses of the results using factors such as age less than 65 years, non-DM status, and stable PD, we could not show any clinical significance for visceral and subcutaneous obesity in PD patients.

Our study has some limitations. We did not determine levels of inflammatory cytokines and adipokines or of insulin resistance, which might have identified an effect of visceral and subcutaneous fat. The small size of the patient sample resulted in low statistical power. Furthermore, we selected patients with a life expectancy of 6 months or more for the study, and those patients had a nutrition status that was better than the nutrition status in patients having a life expectancy of less than 6 months.

\section{CONCLUSIONS}

Increased visceral fat at the initiation of PD is not an independent predictor of poor survival. The impact of visceral or subcutaneous mass on outcomes in patients undergoing PD would be better defined by larger, longterm studies.

\section{DISCLOSURES}

The authors have no conflicts of interest to declare.

\section{REFERENCES}

1. Lee $P, 0^{\prime}$ Neal D, Murphy B, Best J. The role of abdominal adiposity and insulin resistance in dyslipidemia of chronic renal failure. Am J Kidney Dis 1997; 29:54-65.

2. Lu Q, Cheng LT, Wang T, Wan J, Liao LL, Zeng J, et al. Visceral fat, arterial stiffness, and endothelial function in peritoneal dialysis patients. J Ren Nutr 2008; 18:495-502.

3. Ramkumar N, Pappas LM, Beddhu S. Effect of body size and body composition on survival in peritoneal dialysis patients. Perit Dial Int 2005; 25:461-9.

4. Snyder JJ, Foley RN, Gilbertson DT, Vonesh EF, Collins AJ. Body size and outcomes on peritoneal dialysis in the United States. Kidney Int 2003; 64:1838-44.

5. McDonald SP, Collins JF, Rumpsfeld M, Johnson DW. Obesity is a risk factor for peritonitis in the Australian and New Zealand peritoneal dialysis patient populations. Perit Dial Int 2004; 24:340-6.

6. Jager KJ, Merkus MP, Huisman RM, Boeschoten EW, Dekker $\mathrm{FW}$, Korevaar JC, et al. Nutritional status over time in hemodialysis and peritoneal dialysis. J Am Soc Nephrol 2001; 12:1272-9.

7. Choi SJ, Kim NR, Hong SA, Lee WB, Park MY, Kim JK, 
et al. Changes in body fat mass in patients after starting peritoneal dialysis. Perit Dial Int 2011; 31:67-73.

8. Bergström J, Heimbürger 0 , Lindholm B. Calculation of the protein equivalent of total nitrogen appearance from urea appearance. Which formulas should be used? Perit Dial Int 1998; 18:467-73.

9. Keshaviah PR, Emerson PF, Nolph KD. Timely initiation of dialysis: a urea kinetic approach. Am J Kidney Dis 1999; 33:344-8.

10. Churchill DN, Taylor DW, Keshaviah PR, and the CANUSA Peritoneal Dialysis Study Group. Adequacy of dialysis and nutrition in continuous peritoneal dialysis: association with clinical outcomes. J Am Soc Nephrol 1996; 7:198-207.

11. Examination Committee of Criteria for "Obesity Disease" in Japan; Japan Society for the Study of Obesity. New criteria for "obesity disease" in Japan. Circ J 2002; 66:987-92.

12. Yano Y, Haimoto H, Hoshide S, Kabutoya T, Eguchi K, Kario $\mathrm{K}$. Evening heart rate measured at home is associated with visceral obesity and abnormal fat distribution in patients with hypertension. Am J Hypertens 2011; 24:783-8.

13. Gotoh H, Gohda T, Tanimoto M, Gotoh Y, Horikoshi S, Tomino Y. Contribution of subcutaneous fat accumulation to insulin resistance and atherosclerosis in haemodialysis patients. Nephrol Dial Transplant 2009; 24:3474-80.

14. van der Kooy K, Seidell JC. Techniques for the measurement of visceral fat: a practical guide. Int J Obes Relat Metab Disord 1993; 17:187-96.

15. Axelsson J, Møller HJ, Witasp A, Qureshi AR, Carrero JJ, Heimbürger 0 , et al. Changes in fat mass correlate with changes in soluble sCD163, a marker of mature macrophages, in patients with CKD. Am J Kidney Dis 2006; 48:916-25.

16. Kaysen GA, Kotanko P, Zhu F, Sarkar SR, Heymsfield SB, Kuhlmann MK, et al. Estimation of adipose pools in hemodialysis patients from anthropometric measures. $J$ Ren Nutr 2008; 18:473-8.

17. Sanches FM, Avesani CM, Kamimura MA, Lemos MM, Axelsson J, Vasselai $P$, et al. Waist circumference and visceral fat in CKD: a cross-sectional study. Am J Kidney Dis 2008; 52:66-73.

18. Yamauchi T, Kuno T, Takada H, Nagura Y, Kanmatsuse K, Takahashi S. The impact of visceral fat on multiple risk factors and carotid atherosclerosis in chronic haemodialysis patients. Nephrol Dial Transplant 2003; 18:1842-7.
19. Fouque D, Kalantar-Zadeh K, Kopple J, Cano N, Chauveau P, Cuppari L, et al. A proposed nomenclature and diagnostic criteria for protein-energy wasting in acute and chronic kidney disease. Kidney Int 2008; 73:391-8.

20. Kaizu Y, Tsunega Y, Yoneyama T, Sakao T, Hibi I, Miyaji K, et al. Overweight as another nutritional risk factor for the long-term survival of non-diabetic hemodialysis patients. Clin Nephrol 1998; 50:44-50.

21. Goller JL, McMahon JM, Rutledge C, Walker RG, Wood SE. Dialysis adequacy and self-reported health status in a group of CAPD patients. Adv Perit Dial 1997; 13:128-33.

22. Cordeiro AC, Qureshi AR, Stenvinkel $P$, Heimbürger 0 , Axelsson J, Bárány P, et al. Abdominal fat deposition is associated with increased inflammation, protein-energy wasting and worse outcome in patients undergoing haemodialysis. Nephrol Dial Transplant 2010; 25:562-8.

23. Chen W, Guo LJ, Wang T. Extracellular water/intracellular water is a strong predictor of patient survival in incident peritoneal dialysis patients. Blood Purif 2007; 25:260-6.

24. Cheng LT, Tang W, Wang T. Strong association between volume status and nutritional status in peritoneal dialysis patients. Am J Kidney Dis 2005; 45:891-902.

25. Asghar RB, Green S, Engel B, Davies SJ. Relationship of demographic, dietary, and clinical factors to the hydration status of patients on peritoneal dialysis. Perit Dial Int 2004; 24:231-9.

26. Atzmon G, Yang XM, Muzumdar R, Ma XH, Gabriely I, Barzilai N. Differential gene expression between visceral and subcutaneous fat depots. Horm Metab Res 2002; 34:622-8.

27. Einstein FH, Atzmon G, Yang XM, Ma XH, Rincon M, Rudin E, et al. Differential responses of visceral and subcutaneous fat depots to nutrients. Diabetes 2005; 54:672-8.

28. Axelsson J, Rashid Qureshi A, Suliman ME, Honda H, Pecoits-Filho R, Heimbürger 0 , et al. Truncal fat mass as a contributor to inflammation in end-stage renal disease. Am J Clin Nutr 2004; 80:1222-9.

29. Afthentopoulos IE, Oreopoulos DG. Is CAPD an effective treatment for ESRD patients with a weight over $80 \mathrm{~kg}$ ? Clin Nephrol 1997; 47:389-93.

30. Piraino B, Bernardini J, Centa PK, Johnston JR, Sorkin MI. The effect of body weight on CAPD related infections and catheter loss. Perit Dial Int 1991; 11:64-8.

31. Twardowski ZJ, Prowant BF. Exit-site healing post catheter implantation. Perit Dial Int 1996; 16(Suppl 3):S51-70. 